\section{References}

BABIKER, I. E. (1986) Non-compliance in schizophrenia. Psychiatric Developments, 4, 329-337.

BARNES, T. R. E. \& PANTELUS, C. (1992) Treatment resistant schizophrenia. Schizophrenia Monitor, 2, 1-4.

BirchwOOD, M., SMTTH, J., DRURY, V., et al (1993) A self report insight scale for psychosis: Reliability, validity and sensittivity to change. Acta Psychiatrica Scandinavica, 86, 1-6.

BLACKWEL, B. (1972) The drug defaulter. Clinical Pharmacology and Therapeutics, 13, 841-848.

BLESSED, G. \& THOMPSON, P. (1987) Correlation between the 37-item mental test score and abbreviated 10-item mental test score by psychiatric day patients. British Journal of Psychiatry, 182, 206-209.

CORRIGAN, P. W., LiBERMAN, R. P. \& ENGEL, J. D. (1990) From non-compliance to collaboration in the treatment of schizophrenia. American Journal of Psychiatry, 197. 786-789.

KEMP, R. HAYWARD, P., APPLEWhite, G., et al (1996) Compliance therapy in psychotic patients: randomised controlled trial. British Medical Journal, 312, 345-349.

Kussung, W. (1994) Compliance, quality assurance and standards for relapse prevention in schizophrenia. Acta Psychiatrica Scandinavica, 89 (suppl. 382), 16-24.

MACPHERSON, R. JERROM, W. \& HUGHES, A. (1996) A controlled study of education about drug treatment in schizophrenia. British Journal of Psychiatry, 168, 709717.

-. - \& - (1997) Drug refusal among schizophrenic patients in the community. Journal of Mental Health. 6. 141-147.
- Alexander, M., JerRom, W., et al (1998) A survey of patients and keyworker satisfaction with a mental health rehabilitation service. Journal of Mental Health in press.

MARDER, S. R., SWANn, E., Winslade, W. J., et al (1984) A study of medication refusal by involuntary psychiatric patients. Hospital and Community Psychiatry. 36. 724726.

OVERALL. J. E. \& GoRHAM. D. R. (1962) The Brief Psychiatric Rating Scale. Psychiatric Reports, 10, 799.

ROYAL COLLEGE OF PSYCHIATRISTS (1987) Community Treatment Orders: A Discussion Document. London: Royal College of Psychiatrists.

VAN PUTTEN, T. V. (1974) Why do schizophrenic patients refuse to take their drugs? Archives of General Psychiatry, 31. 67-72.

ZrTo, J. M., RouTt, W. W., MrTchell, J. E., et al (1985) Clinical characteristics of hospitalised psychiatric patients who refuse antipsychotic drug therapy. American Journal of Psychiatry. 142, 822-826.

*Rob Macpherson, Consultant Rehabilitation/ General Psychiatrist, Wotton Lawn, Horton Road, Gloucester GL1 3PX; Minh Alexander, Senior Registrar in General Psychiatry. Royal United Hospital; W. Jerrom, Head of Clinical Psychology Services, United Bristol Healthcare Trust, Barrow Hospital, Bristol

*Correspondence

\title{
Model of forensic psychiatric community care
}

\author{
Mary C. Whittle and Mark D. Scally
}

Alms and method the paper describes the establishment of a specialist forensic team providing an integrated model of forensic community psychiatric care.

Results A description is provided of the problems encountered in setting up and running the service and of the ways in which those problems were managed.

Clinical implications The integrated model has the advantage of minimising stigma, providing support and education for staff and enabling forensic expenditure to be provided for a wider group of patients and staff than would otherwise be possible.

Developments in community forensic psychiatry have been hampered by the reluctance of forensic psychiatrists to develop integrated services with general and community psychiatry. Forensic services continue to focus on a parallel system of secure hospital care and remain aloof from local mental health services (Grounds, 1996). Rehabilitation of forensic patients has been hampered by the lack of community services suitable for their needs (MacCulloch \& Bailey, 1991; Parry, 1991). However, the impetus to develop community forensic psychiatric services is increasing. The public remains concerned about violence by mentally ill persons in the community (Ritchie et al, 1994). Community psychiatrists and purchasing authorities are becoming more assertive in seeking forensic advice, particularly for patients on supervision registers (McCarthy et al, 1995). 


\section{Co-working with community peychiatric teams}

The forensic outreach team at the Maudsley Hospital was established in 1994. The service is funded by the Lambeth. Southwark and Lewisham Health Commission. Funds are provided specifically for the purpose and are not dependent on savings achieved elsewhere. The forensic outreach team aims to provide a service to the local community psychiatric teams in the assessment, management and treatment of patients perceived to pose risks to others. Although parallel systems of providing community care for forensic patients are well established (Parry. 1991), the forensic outreach team adopted an integrated rather than parallel approach. The team promotes community-focused links with secure forensic units and encourages the development of specialist skills through the principle of co-working. Co-working involves liaison, consultation and provision of support to psychiatric teams as they manage their patients, rather than a system of transferring clinical responsibility for patients to the forensic outreach team. This enables the service to be flexible, responsive to local need and accessible to greater numbers of patients and staff than would otherwise be possible. The patient retains the benefit of community psychiatric facilities, such as day care, occupational therapy, residential placement and social supports. Continuity of care is maintained by members of the community psychiatric team and the community psychiatrist continues as responsible medical officer. Co-working also ensures that in-patient facilities are available to patients who do not require admission to the regional secure unit. Community psychiatrists retain responsibility for admitting co-worked patients to intensive care and other psychiatric wards when needed. The forensic outreach team can admit patients for whom community forensic nurses are keyworkers to an open forensic ward. This ward provokes a specialist forensic assessment service for patients who do not require hospitalisation in a secure setting. In practice only a small proportion of patients avail themselves of this facility. Over a 12-month period, four patients of the forensic outreach team accounted for six admissions to the ward.

The outreach team is staffed by community forensic nurses, a senior or specialist registrar and a consultant forensic psychiatrist. The forensic directorate provides managerial and secretarial support. Each community forensic nurse has an assigned catchment area corresponding to that of an established community mental health team which provides community psychiatric services to populations of 42000 46000 people. The nurses, all of whom have extensive experience working in forensic units, establish close links with the community psychiatric teams and attend relevant community team meetings. They advise on forensic aspects of mental disorder, mental health legislation and the criminal justice system. They provide informal training to community team staff. The outreach team also holds training seminars on practical aspects of risk assessment and management for the community psychiatric teams. Community forensic nurses take keyworker responsibility for a small number of patients discharged from forensic in-patient units and for patients managed in forensic out-patient clinics. As clinical responsibility for patients is transferred from forensic to community psychiatric teams, forensic outreach nurses continue as coworkers for an agreed period to provide continuity of care. The outreach team provides a psychiatric liaison service to the local court diversion scheme. The forensic community nurses liaise with courts and prisons, providing a professional link with patients assessed by court diversion schemes and communicating with senior nursing staff in prisons. They also provide a nursing-led consultation service to the area probation office.

\section{Referrals and clinical responsibility}

As co-working involves a risk that areas of clinical responsibility could become blurred, regular discussion among team members is emphasised. An increasing number of joint medical and nursing assessments are conducted. Unless an immediate assessment is required, referrals and recommendations are discussed at the weekly outreach team meeting. Referrals are received from in-patient teams; community psychiatric teams; in-patient adolescent services; and the Trust placement service for 'difficult to place' patients. Referrals which the team perceive as likely to need secure forensic care are referred to the regional mediumsecure unit to avoid duplication of work. The team liaises with the regional secure unit if, on assessment, admission of a patient to this service is deemed necessary. Multi-team meetings involving staff from the forensic outreach team, regional secure unit, acute in-patient service and community psychiatric teams have been useful in establishing a clear care plan in cases of disagreement between general and forensic teams on matters of risk and discharge from hospital.

A number of initial referrals did not convey clearly the indication for a forensic assessment. Others contained a covert request for transfer of clinical responsibility. Urgent risk assessments were sought for in-patients who had been 
allowed unsupervised leave into the community or arrived after the patient had been discharged. In other cases, although discharge arrangements and community placement had already been arranged, the decision to discharge the patient seemed contingent on the 'forensic' opinion. The introduction of formal referral forms and increased awareness by community teams of the role of the forensic outreach team has decreased such problems considerably.

The maintenance of clear lines of clinical responsibility was jeopardised occasionally as forensic nurses sought advice from the team about patients for whom they provided a coworking service but for whom the community psychiatrist was the responsible medical officer. This has been addressed by instituting consultation meetings to which the community psychiatrist is invited. Consultation meetings have the added advantage of providing a forum for community teams to present difficult cases for advice in a relatively informal manner.

Community forensic nurses encountered an expectation that they would function as an integral member of community psychiatric teams, acting as storm troopers for 'difficult' patients and keyworkers for patients with a propensity for violence or those registered on the supervision register. As the role of the community forensic nurse was established, a tiered method of co-working evolved. Care planning and personal contact with the most challenging patients is conducted jointly by forensic and community nurses. For other patients, a combined nursing care plan entails close liaison between nurses from both teams but flexible and separate patient contact. For a third group, forensic nursing input is limited to attending clinical reviews by the community psychiatric team in an advisory capacity.

\section{Discussion}

The structure of the forensic outreach team has provided support, education and a forum to share experience for both community and forensic mental health workers. In following an integrated model of psychiatric care it diminishes the stigma of a 'forensic' label and encourages integration of mentally disordered offenders into community psychiatric facilities. This model of an integrated community forensic service enables forensic expertise to reach a wider group of patients than would otherwise be possible with limited resources. Despite initial scepticism about co-working, feedback from community mental health teams has been positive and referrals to and consultation with the forensic outreach team are increasing.

The support of the local purchasing authority and forensic directorate management has facilitated the team's efforts to find efficient ways of working with other specialist psychiatric services. Local psychiatric teams have also been willing to explore new forms of liaison with forensic services. Such support is of paramount importance if community forensic psychiatric services are to develop in a manner which will enable them to meet differing local needs. The challenge for forensic psychiatry is to achieve this in a climate of competition for resources both within the speciality and from general psychiatry (Fraser, 1994) and in which there is an increasing perception that funding decisions discriminate in favour of violent patients.

\section{Acknowledgement}

We thank Dr Paul Bowden for his helpful comments on this paper.

\section{References}

FRASER, K. (1994) Resource requirements in forensic psychiatry. Joumal of Forensic Psychiatry, 8. 478-482. Grounds, A. (1996) Forensic psychiatry for the millennium. Joumal of Forensic Psychiatry. 7. 221-227.

MACCULLOCH, M. \& BALEY, J. (1991) Issues in the provision and evaluation of forensic services. Journal of Forensic Psychiatry. 2. 247-265.

MCCARTHY. A.. ROY. D.. HoLlOWAY, F., et al (1995) Supervision registers and the care programme approach: a practical solution. Psychiatric Bulletin. 19. 195-199.

PARRY, J. (1991) Community care for mentally ill offenders. Nursing Standard, 5, 29-33.

RITCHIE, J. H., Dick. D. \& LINGHAM, R. (1994) The Report of the Inquiry into the Care and Treatment of Christopher Clunis. London: HMSO.

*Mary C. Whittle, Consultant Forensic Psychiatrist, John Howard Centre, 2 Crozter Terrace, Hackney, London E9 6AT; and Mark D. Scally, Community Forensic Nurse, Maudsley Hospital, London

*Correspondence 